Article

\title{
Inhibition of Cdk5 Ameliorates Skeletal Bone Loss in Glucocorticoid-Treated Mice
}

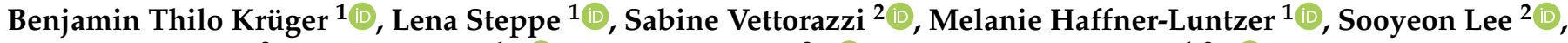 \\ Ann-Kristin Dorn ${ }^{2}$, Anita Ignatius $1, * \mathbb{D}$, Jan Tuckermann ${ }^{2, * \mathbb{B}}$ and Mubashir Ahmad ${ }^{1,2, * \mathbb{C}}$
}

1 Institute of Orthopedic Research and Biomechanics, Ulm University, Helmholtzstrasse 14, 89081 Ulm, Germany; benjamin.krueger@uni-ulm.de (B.T.K.); lena.steppe@uni-ulm.de (L.S.); melanie.haffner-luntzer@uni-ulm.de (M.H.-L.)

2 Institute of Comparative Molecular Endocrinology (CME), Ulm University, Helmholtzstrasse 8/1, 89081 Ulm, Germany; sabine.vettorazzi@uni-ulm.de (S.V.); sooyeon.lee@uni-ulm.de (S.L.); ann.kristin.picke@gmail.com (A.-K.D.)

* Correspondence: anita.ignatius@uni-ulm.de (A.I.); jan.tuckermann@uni-ulm.de (J.T.); ahmad.mubashir@uni-ulm.de (M.A.)

\section{check for}

updates

Citation: Krüger, B.T.; Steppe, L.; Vettorazzi, S.; Haffner-Luntzer, M.; Lee, S.; Dorn, A.-K.; Ignatius, A.; Tuckermann, J.; Ahmad, M. Inhibition of Cdk5 Ameliorates Skeletal Bone Loss in GlucocorticoidTreated Mice. Biomedicines 2022, 10, 404. https://doi.org/10.3390/ biomedicines 10020404

Academic Editor: Andreas Traweger

Received: 14 January 2022 Accepted: 5 February 2022 Published: 8 February 2022

Publisher's Note: MDPI stays neutral with regard to jurisdictional claims in published maps and institutional affiliations.

Copyright: (c) 2022 by the authors. Licensee MDPI, Basel, Switzerland. This article is an open access article distributed under the terms and conditions of the Creative Commons Attribution (CC BY) license (https:// creativecommons.org/licenses/by/ $4.0 /)$.

\begin{abstract}
Glucocorticoids (GCs) are widely used to treat inflammatory diseases. However, their long-term use leads to glucocorticoid-induced osteoporosis, increasing morbidity and mortality. Both anabolic and anti-resorptive drugs are used to counteract GC-induced bone loss, however, they are expensive and/or have major side effects. Therefore, identifying new targets for cost-effective, small-molecule inhibitors is essential. We recently identified cyclin-dependent kinase 5 (Cdk5) as a suppressor of osteoblast differentiation and showed that its inhibition with roscovitine promoted osteoblastogenesis, thus improving the skeletal bone mass and fracture healing. Here, we assessed whether Cdk5 knockdown or inhibition could also reverse the GC-mediated suppression of osteoblast differentiation, bone loss, and fracture healing. We first demonstrated that $C d k 5$ silencing abolished the dexamethasone (Dex)-induced downregulation of alkaline phosphatase (Alp) activity, osteoblastspecific marker gene expression (Runx2,Sp7, Alpl, and Bglap), and mineralization. Similarly, Cdk5 inhibition rescued Dex-induced suppression of Alp activity. We further demonstrated that Cdk5 inhibition reversed prednisolone (Pred)-induced bone loss in mice, due to reduced osteoclastogenesis rather than improved osteoblastogenesis. Moreover, we revealed that C $\mathrm{dk} 5$ inhibition failed to improve Pred-mediated impaired fracture healing. Taken together, we demonstrated that Cdk5 inhibition with roscovitine ameliorated GC-mediated bone loss but did not reverse GC-induced compromised fracture healing in mice.
\end{abstract}

Keywords: osteoblasts; osteoclasts; osteocytes; bone; cyclin-dependent kinase 5; roscovitine; glucocorticoids; glucocorticoid-induced osteoporosis; fracture healing

\section{Introduction}

Glucocorticoids (GCs) are potent anti-inflammatory agents to treat inflammatory diseases including rheumatoid arthritis, chronic obstructive pulmonary disease, and inflammatory bowel disease [1-5]. However, long-term GC therapy is associated with glucocorticoid-induced osteoporosis (GIO), the most prevalent form of secondary osteoporosis [6,7]. The adverse effects of long-term GC therapy on bone increase the risk for fragility fractures in a dose-dependent manner, which exacerbates the cause of disability and mortality [8,9]. Supraphysiological GC levels reduce bone mass primarily by decreasing osteoblast function and bone formation [10-17]. In addition, high-dose GCs increase the receptor activator of nuclear factor kappa-B ligand (RANKL) and reduce osteoprotegerin (OPG) levels, thus inducing osteoclastogenesis and bone resorption [14,18,19].

In addition to their well-known negative effects on bone mass, GCs also influence the complex process of bone fracture healing that includes the consecutive phases of 
inflammation, soft and hard callus formation, and remodeling until the restoration of the original bone structure and shape [20]. Recently, endogenous GC signaling was shown to be essential for effective bone regeneration [21-23]. However, exogenous treatment with supraphysiological GC doses significantly reduces bone formation after fracture and the quality of the newly formed bone [24-28].

Current treatment regimens for GIO include anti-resorptive and osteoanabolic drugs, including oral and intravenous bisphosphonates (BPs), denosumab, human parathyroid hormone 1-34 (hPTH 1-34), and supplementation of calcium and vitamin D [29-37]. Indeed, these treatments have proven to ameliorate bone loss in GIO and reduce the burden of GCmediated fractures [38-40]. Similarly, BP treatment reversed GC-mediated, compromised fracture healing in a pre-clinical study in rats [41]. Contrarily, osteoanabolic therapy with hPTH 1-34 failed to improve fracture healing in GC-treated mice [42]. Although some anti-osteoporotic drugs show a promising outcome in both GC-mediated GIO and impaired fracture healing, they either are expensive or have major side effects [43-47]. Therefore, the identification of targets for cost-effective, small-molecule inhibitors with minimal side effects is of utmost importance.

Cyclin-dependent kinase 5 (Cdk5), a member of the proline-directed serine/threonine cyclin-dependent kinase family, largely controls a number of neuronal functions and is known to be a major player in the pathogenesis of neurodegenerative diseases [48-52]. Recently, we identified Cdk5 as a strong suppressor of osteoblast differentiation and showed that its inhibition with the small-molecule inhibitor, roscovitine, increased bone mass and improved fracture healing in skeletally healthy mice [53]. On the basis of these observations, we here investigated whether Cdk5 inhibition with roscovitine could also reverse GC-induced bone loss and compromised fracture healing.

\section{Materials and Methods}

\subsection{Isolation of Primary Murine Calvarial Osteoblasts}

Primary calvarial osteoblast isolation was performed using neonatal mouse calvaria of 2-5-day-old pups as previously described [54,55]. Briefly, the calvariae were isolated in $1 \mathrm{~mL}$ digestion solution $(0.2 \% w / v$ each of collagenase A and dispase II (Roche, Basel, Switzerland)) and incubated at $37^{\circ} \mathrm{C}$ for $10 \mathrm{~min}$ at $700 \mathrm{rpm}$ on a shaker. The digestion was performed five times, and all but the first supernatant were collected in $15 \mathrm{~mL}$ falcons containing $500 \mu \mathrm{L}$ fetal bovine serum (GE Healthcare, Chicago, IL, USA). The collected supernatant was centrifuged $(252 \times g ; 5 \mathrm{~min}$; room temperature (RT)), resuspended in $3 \mathrm{~mL}$ complete $\alpha$-minimum essential medium (ThermoFisher Scientific, Waltham, MA, USA) and placed in a six-well plate. Following overnight incubation $\left(37^{\circ} \mathrm{C} ; 5 \% \mathrm{CO}_{2}\right)$, the medium was replaced with a fresh medium. The experiments were performed at an $80 \%$ confluency as previously described [53,54].

\subsection{Small Interfering RNA (siRNA) Transfection}

SMARTpool non-targeting siRNA control (siNT) and Cdk5-specific siRNA (siCdk5) were purchased from Horizon Discovery (Waterbeach, UK). The transfection was performed using a final concentration of $20 \mathrm{nM}$ siRNA with $0.125 \%$ Lipofectamine RNAiMAX transfection reagent (Life Technologies, ThermoFisher Scientific, Waltham, MA, USA), as previously described [54]. The siRNA sequences used are listed in Table 1.

\subsection{Murine Primary Calvarial Osteoblast Differentiation}

For experiments with primary murine calvarial osteoblasts, the cells were seeded at a confluency of 12,000 cells $/ \mathrm{cm}^{2}$. After $48 \mathrm{~h}$, the cells were differentiated by adding an osteogenic induction medium $(100 \mu \mathrm{g} / \mathrm{mL}(+)$-sodium L-ascorbate and $5 \mathrm{mM} \beta$-glycerophosphate (Sigma-Aldrich, St. Louis, MO, USA)). The osteogenic induction medium was refreshed every third day. 
Table 1. Mouse siRNA sequences used in this study.

\begin{tabular}{|c|c|c|c|}
\hline Gene Symbol & Gene Name & Gene ID & Reverse Primer $\left(5^{\prime}-3^{\prime}\right)$ \\
\hline Non-targeting & - & - & $\begin{array}{l}\text { UAAGGCUAUGAAGAGAUAC } \\
\text { AUGUAUUGGCCUGUAUUAG } \\
\text { AUGAACGUGAAUUGCUCAA } \\
\text { UGGUUUACAUGUCGACUAA }\end{array}$ \\
\hline$C d k 5$ & $\begin{array}{l}\text { Cyclin-dependent } \\
\text { kinase } 5\end{array}$ & 12568 & $\begin{array}{l}\text { GGAGAUCUGUCUACUCAAA } \\
\text { UAUAAGCCCUACCCAAUGU } \\
\text { GCAACGUGCUACAUAGGGA } \\
\text { CAACAUCCUUGGUGAACGU }\end{array}$ \\
\hline
\end{tabular}

Treatment with roscovitine $(0.16 \mu \mathrm{M})$ (Selleckchem, Houston, TX, USA) was performed in an osteogenic induction medium, as previously described [53]. An ethanol vehicle was used at a concentration of $0.01 \%$ as a control. Treatment with roscovitine was performed every third day until the termination of the experiment.

\subsection{PrestoBlue Cell Viability Assay}

Cell viability was tested using the PrestoBlue cell viability reagent (Thermo Fisher Scientific, Waltham, MA, USA) according to the manufacturer's instructions. Briefly, $3.2 \mathrm{~mL}$ of the medium were removed from $60 \mathrm{~mm}$ dishes, followed by the addition of $200 \mu \mathrm{L}$ cell viability reagent. In parallel, in a 96-well plate, the medium and the cell viability reagent were mixed in a volume ratio of 9:1 to obtain a final volume of $100 \mu \mathrm{L}$ that served as a blank. After incubating the plates $\left(37^{\circ} \mathrm{C} ; 5 \% \mathrm{CO}_{2}\right)$ for $30 \mathrm{~min}, 100 \mu \mathrm{L}$ aliquots were measured against the blank at a $570 \mathrm{~nm}$ absorbance using a Dynex Opsys MR microplate reader (Aspect Scientific, Cheshire, UK).

\subsection{Alkaline Phosphatase (Alp) and Alizarin Red S (ARS) Staining}

For quantitative Alp, primary murine calvarial osteoblasts were reversely transfected and seeded in a 384-well plate. The cells were differentiated by adding an osteogenic induction medium, fixed and stained with ELF 97 (Thermo Fisher Scientific, Waltham, MA, USA) for Alp, and DRAQ5 (BioStatus Ltd., Loughborough, UK) for nuclei, and were analyzed as previously described [54]. For Cdk5 inhibition in vitro, primary murine calvarial osteoblasts were treated with either a vehicle or roscovitine $(0.16 \mu \mathrm{M})$ for six days as previously described [53].

For qualitative and quantitative ARS (Sigma-Aldrich, St. Louis, MO, USA) staining, the primary calvarial osteoblasts were fixed with $4 \%$ paraformaldehyde (PFA) (10 min; RT) and incubated with 1\% ARS (1 h; RT). The excessive ARS was removed by washing with $1 \times$ phosphate-buffered saline (PBS), and stereomicroscopic images were obtained using a Leica microscope (Leica Camera AG, Wetzlar, Germany). For quantitative evaluation, the ARS stain was extracted by the acetic acid method and neutralization with ammonium hydroxide as previously described [56]. The colorimetric measurement of the extracted solution was performed using a Dynex Opsys MR microplate reader (Dynex Technologies $\mathrm{GmbH}$, Denkendorf, Germany) at an absorption of $405 \mathrm{~nm}$. Finally, the measurements were normalized to the cell viability.

\subsection{RNA Isolation, cDNA Synthesis, and Real-Time Polymerase Chain Reaction (RT-PCR)}

RNA isolation was performed using a RNeasy kit (Qiagen, Hilden, Germany) according to the manufacturer's instructions. Following the isolation procedure, $1 \mu \mathrm{g}$ RNA was used for reverse transcription using a RevertAid H Minus reverse transcriptase kit (Fermentas, Waltham, MA, USA) or a high-capacity cDNA kit (Thermo Fisher Scientific, Waltham, MA, USA). RT-PCR was performed using a ViiA 7 PCR system (Applied Biosystems, Waltham, MA, USA), and relative mRNA concentrations were normalized to $\beta$-actin (Actb) using the $\Delta \Delta C \mathrm{t}$ method. The mouse primer sequences used in this study are listed in Table 2. 
Table 2. Oligonucleotide primer sequences from mice used in real-time polymerase chain reaction (RT-PCR).

\begin{tabular}{|c|c|c|c|}
\hline Gene Symbol & Gene ID & Forward Primer $\left(5^{\prime}-3^{\prime}\right)$ & Reverse Primer $\left(5^{\prime}-3^{\prime}\right)$ \\
\hline Cdk5 & 12568 & TGGACCCTGAGATTGTGAAGT & GACAGAATCCCAGGCCTTTC \\
\hline Runx2 & 12393 & TGTTCTCTGATCGCCTCAGTG & CCTGGGATCTGTAATCTGACTCT \\
\hline$S p 7$ & 170574 & СССАСССТТСССТСАСТСАТ & CCTTGTACCACGAGCCATAGG \\
\hline Alpl & 11647 & GCTGATCATTCCCACGTTTT & CTGGGCCTGGTAGTTGTTGT \\
\hline Bglap & 12096 & TCTGACAAAGCCTTCATGTCCA & CGGTCTTCAAGCCATACTGGTC \\
\hline Rankl & 21943 & TCACCATTCGGATGAGTCTG & ACTTGTGGCTCTGATGTTCC \\
\hline Opg & 18383 & CCTGAGGCCCAGCCATTT & CTTGGCCCAGCCTCGAT \\
\hline Actb & 11461 & ССТTGCCCTGACCACTCTTA & ACACTGGGCTGCAATACACA \\
\hline
\end{tabular}

\subsection{Protein Isolation, Quantification, and Western Blotting}

The whole cell protein was isolated using a radioimmunoprecipitation assay buffer and quantified using a Pierce BCA protein assay kit (ThermoFisher Scientific, Waltham, MA, USA). We used $30 \mu \mathrm{g}$ protein from each sample and subjected them to western blotting as previously described [54]. We used antibodies against Cdk5 (Cell Signaling Technology, Danvers, MA, USA) and $\alpha$-tubulin (Sigma-Aldrich, St. Louis, MO, USA). The band intensities of western blots were quantified using Fiji ImageJ [57].

\subsection{Animals}

All mouse experiments were in compliance with the international regulations for the care and use of laboratory animals with the approval of the local ethical committee (No.1245/1402 Regierungspräsidium Tübingen, Germany). Eleven- and 13-week-old wildtype female and male BALB/cAnNCrl mice were separately maintained in single house units under controlled standard conditions (Makrolon type II long; $530 \mathrm{~cm}^{2}$ ), with a $12 \mathrm{~h}$ light and dark circadian rhythm with water and food (Ssniff, Soest, Germany) ad libitum at $23{ }^{\circ} \mathrm{C}$ and a humidity of $55 \% \pm 10 \%$ ) in a pathogen-free animal facility at Ulm University. To reduce the number of mice, we followed the replace, reduce, refine (3Rs) principle for the ethical use of animals. Therefore, we here used the control group (sham/vehicle) derived from our previous study [53], as these experiments were run in parallel.

\subsection{GIO Model}

Eleven-week-old wild-type female BALB/cAnNCrl mice (Charles River Laboratories, Wilmington, MA, USA) received a subcutaneous slow-release sham- or prednisolone (Pred)pellet (12 mg/kg/day) (Innovative Research of America, Sarasota, FL, USA) at the neck, as previously described [58]. The mice were injected intraperitoneally (i.p.) with either a vehicle (5\% dimethyl sulfoxide (DMSO), 10\% kolliphor EL (Sigma-Aldrich, Taufkirchen, Germany), $85 \% 1 \times$ PBS), or roscovitine (150 mg $/ \mathrm{kg}$ ) (LC Laboratories, Woburn, MA, USA), three times a week for two weeks, as previously described [53]. The surgery was performed under general anesthesia (2 volume percent (vol\%) isoflurane (Baxter, Unterschleißheim, Germany)). After two weeks, the mice were euthanized by an overdose of isoflurane, and the femora were collected for further analyses.

\subsection{Fracture Healing Model}

To study fracture healing, we used a standardized osteotomy model as previously described [59]. The osteotomy was performed at the right femur diaphysis of 12-week-old wild-type male BALB/cAnNCrl mice (Charles River Laboratories, Wilmington, MA, USA). All surgeries were performed under general anesthesia ( $2 \mathrm{vol} \%$ isoflurane). The mice first received clindamycin ( $45 \mathrm{mg} / \mathrm{kg}$ ) (MIP Pharma Holding $\mathrm{GmbH}$, Blieskastel, Germany) as an anti-infective treatment just prior to the surgery, and tramadol-hydrochloride in the 
drinking water (25 mg/L) (Grünenthal, Aachen, Germany) as pain medication one day prior until day three post-surgery, as previously described [59]. During the procedure, the right femur was exposed and stabilized using a semi-rigid external fixator with an axial stiffness of $3 \mathrm{~N} / \mathrm{mm}$ and four mini-Schanz screws (RISystem, Davos, Switzerland). A midshaft osteotomy was performed using a gigli wire saw $(0.4 \mathrm{~mm}$ in diameter). Additionally, the mice received a subcutaneous slow-release sham- or prednisolone-pellet $(12 \mathrm{mg} / \mathrm{kg} /$ day) $[10,58]$ and were further injected i.p. with either a vehicle (5\% DMSO, $10 \%$ kolliphor EL, and $85 \% 1 \times$ PBS) or roscovitine $(150 \mathrm{mg} / \mathrm{kg})$ (Selleckchem, Houston, TX, USA), every second day for 14 or 23 days. After the respective time-points, the mice were euthanized by an overdose of isoflurane, and osteotomized femora were collected for further analyses.

\subsection{Biomechanical Testing of the Fractured Femurs}

At day 23 post-surgery, fractured femurs were subjected to biomechanical testing using a non-destructive three-point bending test in a universal material testing machine, Zwick Z10 (Zwick Roell, Ulm, Germany), to assess the functional healing outcome, as previously described [59]. Briefly, after the fixation of the proximal end of the femur into a hinge joint of the testing setup, an increasing load up to a maximum of $2 \mathrm{~N}$ was applied to the middle of the callus ( $2 \mathrm{~mm} / \mathrm{min}$ ). Flexural rigidity was calculated using the slope $(k)$ of the load-displacement curve in the linear region [59].

\subsection{Microcomputed Tomography ( $\mu \mathrm{CT}$ ) Analysis}

Intact femurs were analyzed using a high-resolution $\mu \mathrm{CT}$ Skyscan 1176 scanner (Bruker Corporation, Billerica, MA, USA). Images at a $9 \mu \mathrm{m}$ voxel resolution were acquired using a $50 \mathrm{kV}$ X-ray voltage, a $200 \mu \mathrm{A}$ current, and a $0.5 \mathrm{~mm}$ aluminum filter with a $1^{\circ}$ rotation step. Following reconstruction using NRecon and DataViewer (Bruker Corporation, Billerica, MA, USA), the trabecular and cortical bone analysis was performed at the 0.215 and $1.935 \mathrm{~mm}$ proximal of the growth plate using 1.29 - and $0.43-\mathrm{mm}$ regions of interest, respectively. The structural analysis was performed using the CTAn software (Bruker Corporation, Billerica, MA, USA). Three-dimensional images were created using CTVox (Bruker Corporation, Billerica, MA, USA).

In the fractured femora, the region of interest was set as the periosteal callus between both inner pinholes. The bone volume fraction (BV/TV) was measured under a global threshold of $642 \mathrm{mg}$ hydroxyapatite $/ \mathrm{cm}^{3}$ as previously described [60]. All the measurements were performed in accordance with the guidelines of the American Society for Bone and Mineral Research (ASBMR) [61].

\subsection{Histomorphometry}

For static bone histomorphometry, femurs were isolated, fixed in 4\% PFA for three days and decalcified with $15 \%$ ethylenediamine tetraacetic acid for 10 days followed by paraffin embedding, as previously described [53,62]. Femur sections of seven micrometers were cut and stained for tartrate-resistant acid phosphatase (TRAP) as previously described [63]. Osteoclasts were counted as multinucleated TRAP-positive cells, whereas osteoblasts were counted as cubic-shaped cells with visible cytoplasm. The following cellular parameters were measured: osteoclast surface per bone surface (Oc.S/BS), osteoclast number per bone perimeter (Oc.N/B.Pm), osteoblast surface per bone surface (Ob.S/BS), and osteoblast number per bone perimeter (Ob.N/B.Pm), using Osteomeasure software (Osteometrics, Decatur, IL, USA) according to the ASBMR guidelines [64,65].

Fractured femora were stained with Safranin-O/Fast Green to analyze the callus, bone, cartilage, and soft tissue areas, using Leica LASX image analysis software (Leica, Heerbrugg, Switzerland).

For dynamic bone histomorphometry, the mice received i.p. calcein injections nine and two days prior to sacrifice as previously described $[63,64,66]$. Femurs were fixed in $4 \%$ PFA and embedded in methyl methacrylate as previously described $[64,66]$. Femur 
sections of seven micrometers were cut to determine the bone formation rate (BFR) and the mineral apposition rate (MAR) using the Osteomeasure software (Osteometrics, Decatur, IL, USA).

\subsection{N-Terminal Propeptide of Type I Procollagen (PINP) and C-Terminal Telopeptides of Type I Collagen (CTX-I) ELISAs}

The blood of the mice was collected in heparin-coated tubes and centrifuged at $2000 \times g$ for $10 \mathrm{~min}$ at RT to collect the plasma. ELISAs for PINP and CTX-I (Immunodiagnostic Systems, East Boldon, UK) were performed according to the manufacturer's instructions.

\subsection{Statistical Analysis}

Data are represented as box and whisker plots with the minimum to the maximum as well as superimposing all of the data points. Statistical differences between the groups were determined by ordinary one-way ANOVA using Tukey's multiple comparison test. A $p$-value less than 0.05 was considered to be statistically significantly different $\left({ }^{*} p<0.05\right.$, $\left.{ }^{* *} p<0.01,{ }^{* * *} p<0.001\right)$.

\section{Results}

\subsection{Cdk5 Deletion or Inhibition Antagonizes Suppressive Effects of GCs on Osteoblast Differentiation and Mineralization}

Dexamethasone (Dex), a widely used synthetic GC, was shown to suppress osteogenic differentiation and mineralization $[10,67,68]$. To investigate whether $C d k 5$ depletion can affect Dex-mediated osteoblast suppression, we transfected primary murine calvarial osteoblasts with non-targeting siRNA ( $\mathrm{iNT}$ ) or Cdk5-specific siRNA (siCdk5) and induced them into the osteogenic lineage in the presence or absence of $1 \mu \mathrm{M}$ Dex. First, we found that $C d k 5$ mRNA and protein expression was not regulated by Dex treatment and that it was significantly reduced upon siRNA knockdown (Figure 1A-C). We further showed that the Dex treatment significantly reduced cellular Alp activity, while the co-treatment with siCdk5 abrogated the GC-induced suppression of Alp activity (Figure 1D,E). Furthermore, Dex treatment reduced the expression of osteoblast-specific transcription factors and marker genes such as Runx2,Sp7,Alpl, and Bglap, whereas the co-treatment with siCdk5 rescued their expression (Figure $1 \mathrm{~F}-\mathrm{I}$ ). Moreover, as demonstrated by Alizarin red staining, in vitro matrix mineralization was significantly reduced by Dex treatment, whereas this was ameliorated by co-treatment with siCdk5 (Figure 1J,K).

Recently, we reported that Cdk5 inhibition with roscovitine enhances osteoblast differentiation and bone formation [53]. Therefore, to determine whether Cdk5 inhibition with roscovitine can also affect Dex-induced osteoblast suppression, we treated primary murine calvarial osteoblasts with either a vehicle or roscovitine $(0.16 \mu \mathrm{M})$ in the presence or absence of $1 \mu \mathrm{M}$ Dex. Consistent with the siRNA data (Figure $1 \mathrm{~A}-\mathrm{K}$ ), we showed that the roscovitine treatment reversed the GC-mediated suppression of osteoblast function (Figure 1L,M). Taken together, these results confirmed that Cdk5 deletion or inhibition counteracted the Dex-mediated suppression of osteoblast differentiation and mineralization in vitro.

\subsection{Cdk5 Inhibition Antagonizes GC-Mediated Bone Loss by Reducing Osteoclastogenesis}

To investigate whether roscovitine treatment affects GC-mediated bone loss in vivo, we implanted a sham or Pred pellet in wild-type mice and treated them with either a vehicle or roscovitine for 14 days (Figure $2 \mathrm{~A}$ ). The $\mu \mathrm{CT}$ analysis revealed a significant loss of bone mass in the distal femurs of Pred-treated mice. This was due to decreases in trabecular thickness and number, but increased trabecular separation (Figure 2B-F). Importantly, the roscovitine treatment abrogated these Pred-mediated deleterious effects on bone mass (Figure 2B-F). In addition, the crossectional thickness was significantly reduced in the Pred-treated mice, which was reversed by roscovitine co-treatment (Figure 2G). 

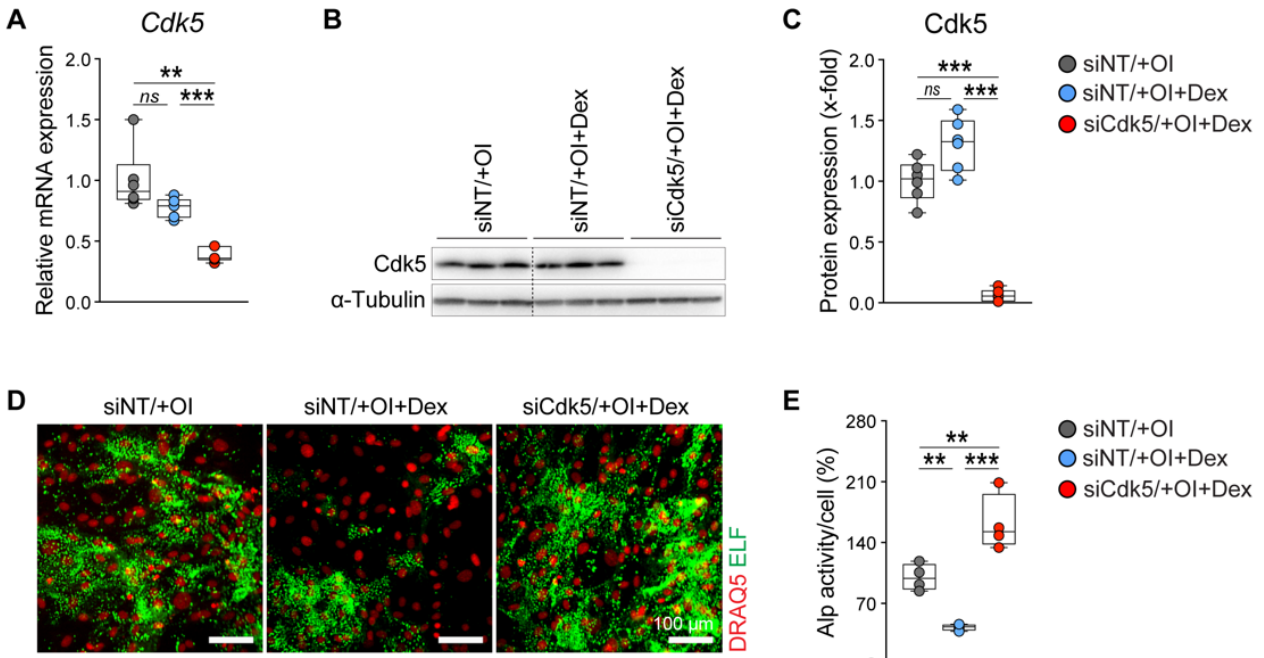

E
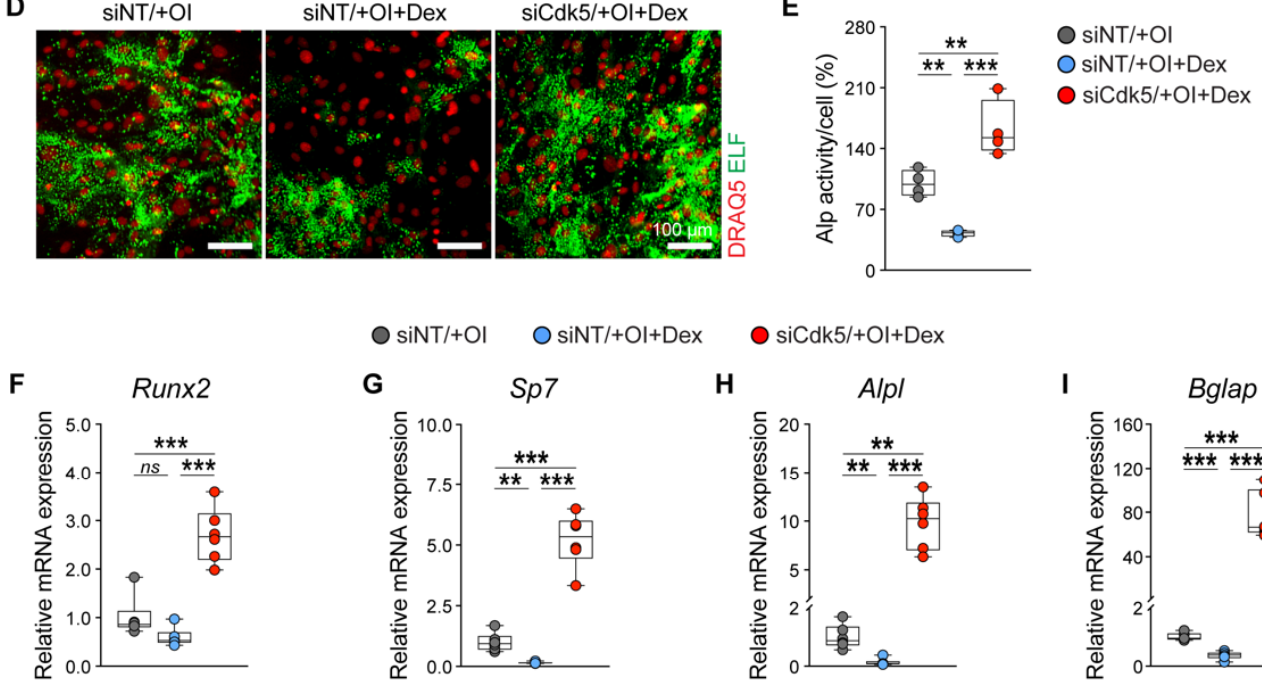

O siNT/+Ol O siNT/+Ol+Dex
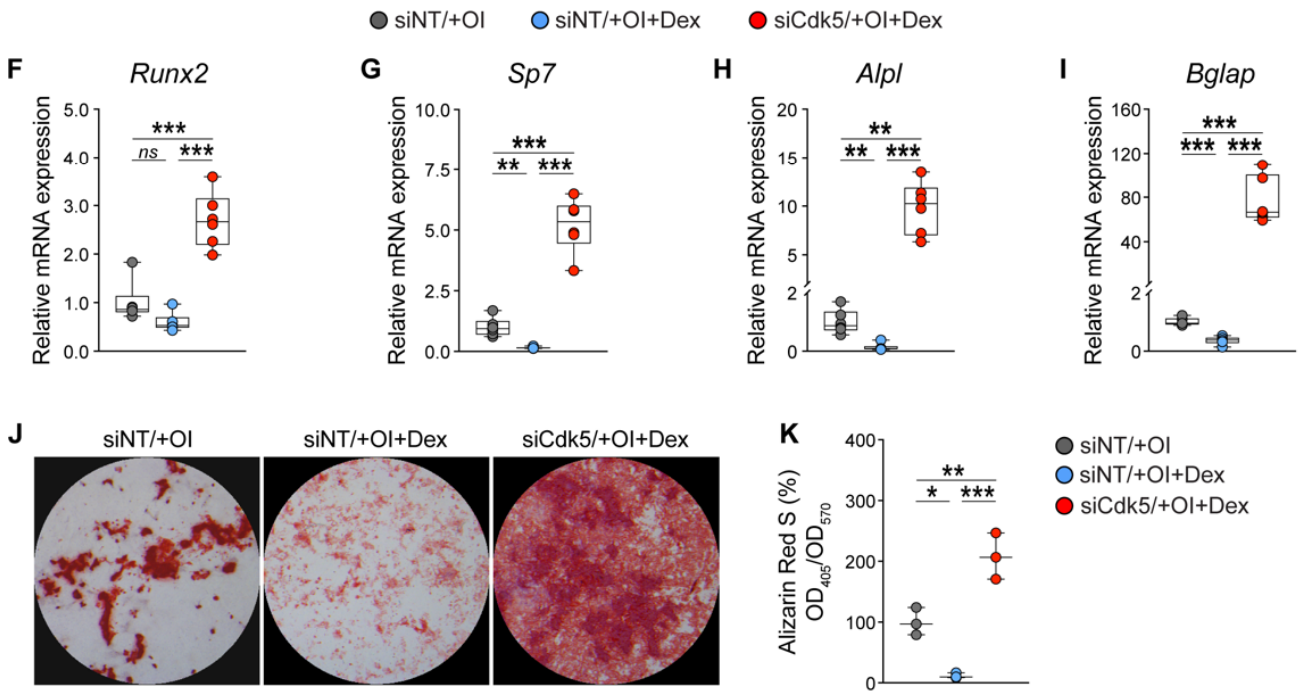

O $\operatorname{sinT} /+\mathrm{OI}$

G

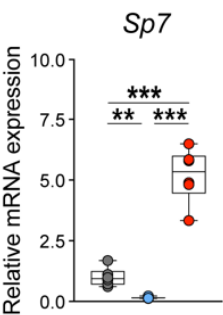

siNT/+Ol+Dex

siCdk5/+Ol+Dex

L
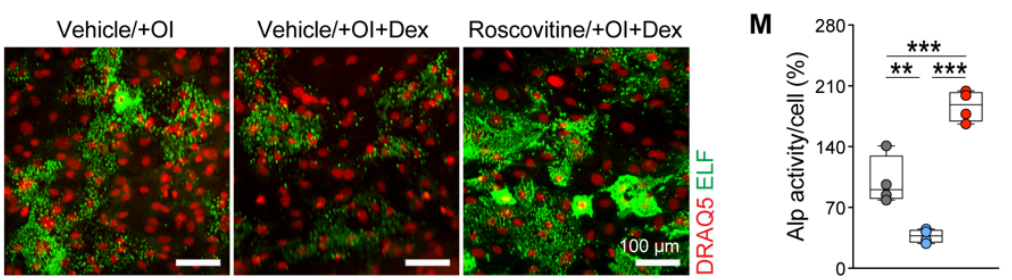

O Vehicle/+OI

Vehicle/+Ol+Dex

Roscovitine/+OI+Dex

Figure 1. Glucocorticoid (GC)-mediated suppression of osteoblast differentiation and mineralization is reversed by Cdk5 deletion or inhibition. Primary murine calvarial osteoblasts were transfected either with non-targeting siRNA ( $\mathrm{siNT}$ ) or Cdk5-specific siRNA (siCdk5) for eight days in the presence or absence of $1 \mu \mathrm{M}$ dexamethasone (Dex): (A) Cdk5 mRNA expression ( $\mathrm{n}=6)$; (B,C) Cdk5 protein levels and its quantification (the siCdk5/+OI group was cropped out as shown with the dotted line. For the original, see Figure S1) $(n=6) ;(D, E)$ representative microscopic images of nuclear (DRAQ5 in red) and Alp (ELF 97 in green) staining upon different treatments and their quantification $(\mathrm{n}=4) ;(\mathbf{F}-\mathbf{I})$ mRNA expression of osteoblast-specific marker genes Runx2, Sp7, Alpl, and Bglap $(\mathrm{n}=6)$; $(\mathrm{J}, \mathbf{K})$ qualitative and quantitative Alizarin Red S staining in primary murine calvarial osteoblasts after 20 days of transfection with siNT or siCdk5, in the presence or absence of $1 \mu \mathrm{M}$ Dex $(\mathrm{n}=3)$; $(\mathbf{L}, \mathbf{M})$ representative microscopic images of nuclear (red) and Alp (green) staining upon different treatments and their quantification in primary murine calvarial osteoblasts after six days of treatment with a vehicle $(\mathrm{EtOH})$ or roscovitine $(0.16 \mu \mathrm{M})$, in the presence or absence of $1 \mu \mathrm{M}$ Dex $(n=4)$. Data are 
represented as box and whisker plots with the minimum to the maximum as well as superimposing all of the data points. Statistical differences between two groups were determined by one-way ANOVA and Tukey's test. ${ }^{*} p<0.05 ;{ }^{* *} p<0.01 ;{ }^{* *} p<0.001$, ns: no significance.

A
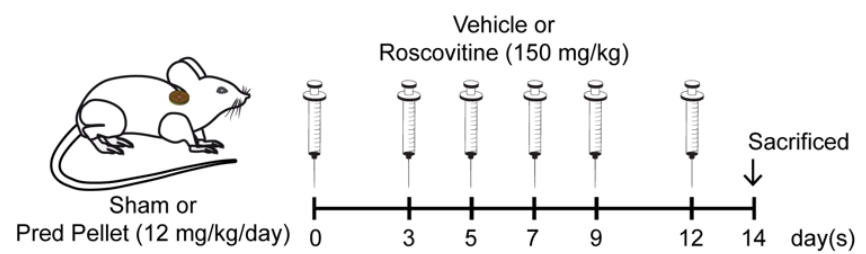

B
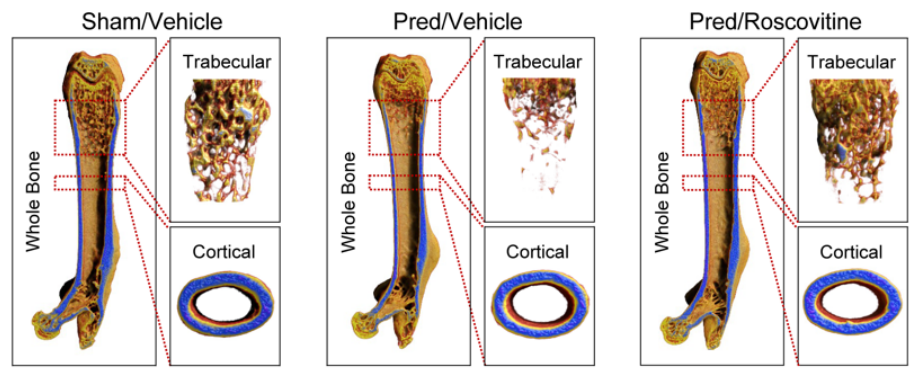

O Sham/Vehicle

\section{E}

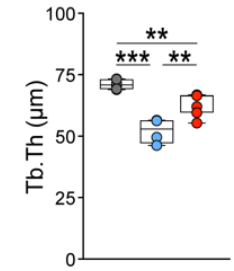

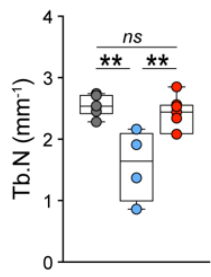

O Pred/Vehicle

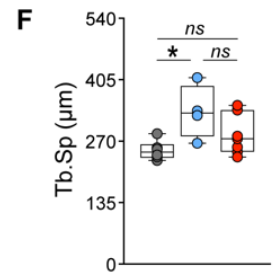

C
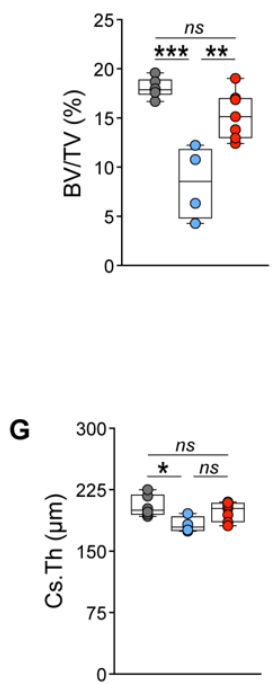

Figure 2. Inhibition of Cdk5 with roscovitine ameliorates GC-mediated loss of bone mass in mice. (A) Experimental setup for the implantation of a sham or prednisolone (Pred)-pellet, followed by treatment with a vehicle or roscovitine (intraperitoneally (i.p.); $150 \mathrm{mg} / \mathrm{kg}$; three times per week) for 14 days. (B) Representative micro-computed tomography $(\mu \mathrm{CT})$ images of whole, trabecular and cortical bone upon different treatments. The calculated femoral trabecular and cortical parameters include the following: (C) bone volume fraction (BV/TV; \%); (D) trabecular thickness (Tb.Th; $\mu \mathrm{m})$; (E) trabecular number (Tb.N; $\mathrm{mm}^{-1}$ ); (F) trabecular separation (Tb.Sp; $\mu \mathrm{m}$ ); and (G) cross-sectional thickness $($ Cs.Th; $\mu \mathrm{m})(\mathrm{n}=4-6)$. Data are represented as box and whisker plots with the minimum to the maximum as well as superimposing all of the data points. Statistical differences between two groups were determined by one-way ANOVA and Tukey's test. * $p<0.05$; ${ }^{* *} p<0.01$; ${ }^{* * *} p<0.001$, ns: no significance.

To determine the effect of the roscovitine treatment on bone cells in vivo, we performed static and dynamic bone histomorphometry. We observed significant decreases in the osteoblast surface and number in both trabecular and cortical bone in Pred-treated mice, which was not reversed by the roscovitine co-treatment (Figures 3A,B and S2A,B). The dynamic bone histomorphometry confirmed these findings: MAR and BFR were reduced in Pred-treated mice, and this was not reversed by co-treatment with roscovitine (Figures 3C-E and S2C-E). In addition, the decreased osteocyte number induced by the Pred treatment was not rescued by synergistic treatment with roscovitine (Figures $3 \mathrm{~F}$ and S2F). By contrast, the osteoclast surface and number, which were significantly increased after the Pred treatment in both trabecular and cortical bone, were reduced to control levels by the roscovitine co-treatment (Figures 3G-I and S2G,H). These results were further confirmed by reduced plasma PINP levels and increased CTX-I levels in the Pred-treated mice, indicating reduced bone formation and increased bone resorption, respectively (Figure 3J,K). 
However, only the CTX-I levels returned to control levels in mice that received both Pred and roscovitine treatments (Figure 3J,K).
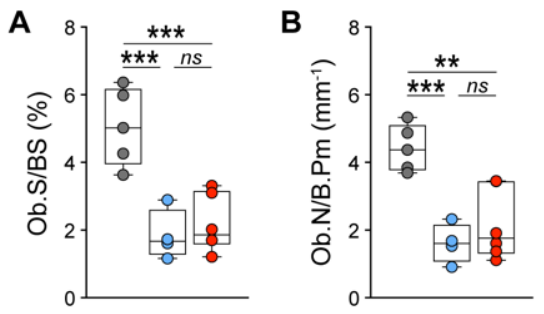

C

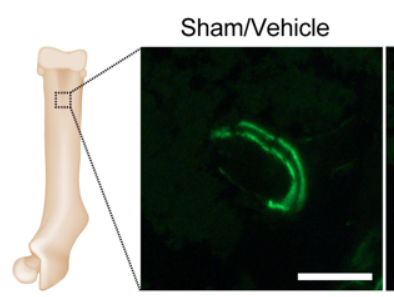

Pred/Vehicle

Pred/Roscovitine

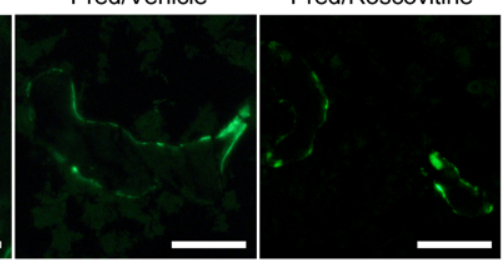

O Sham/Vehicle OPred/Vehicle
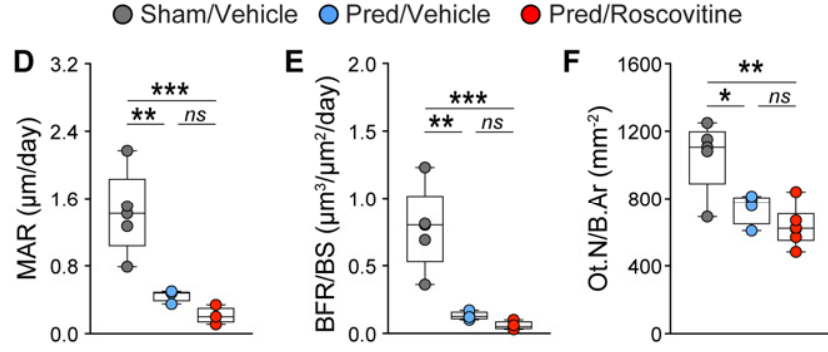

G
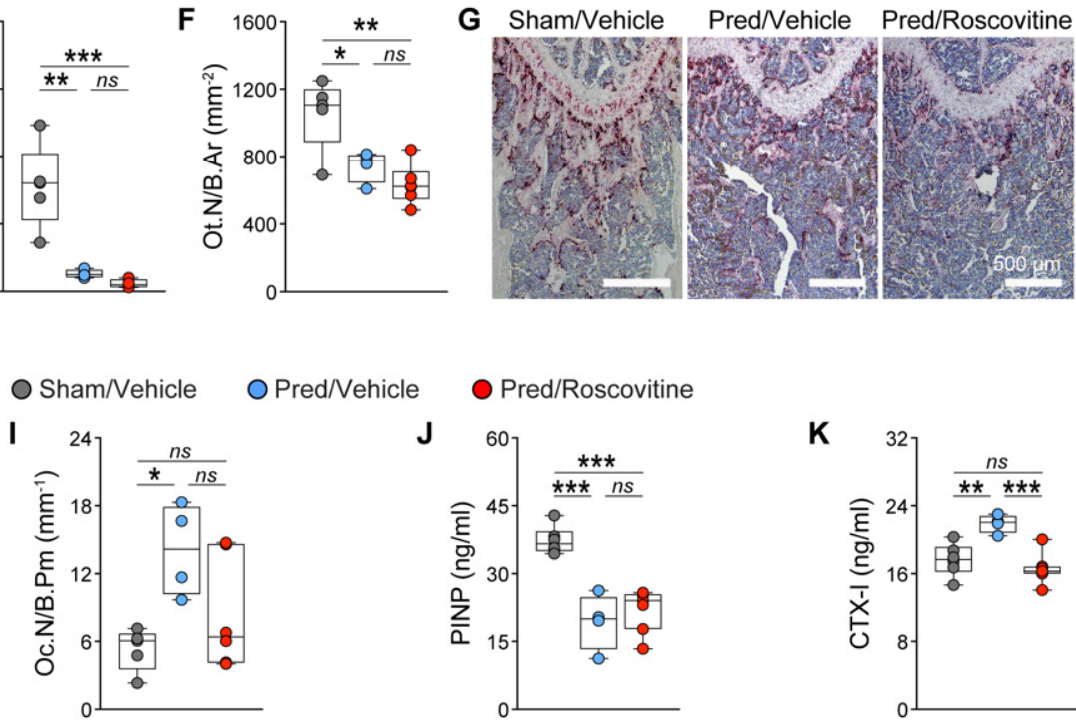

O Pred/Vehicle

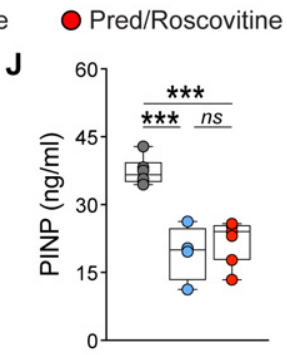

K

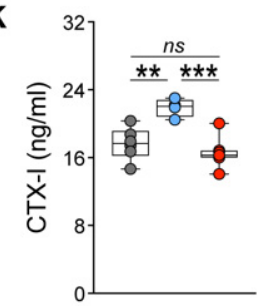

Figure 3. Inhibition of Cdk5 with roscovitine alleviates GC-mediated bone loss by reducing osteoclastogenesis. Static and dynamic bone histomorphometry were performed from different treatments, and the following parameters were calculated from trabecular bone: (A) osteoblast surface per bone surface (Ob.S/BS; \%); (B) osteoblast number per bone parameter (Ob.N/B.Pm; mm $\left.{ }^{-1}\right)$; (C) representative images of dual calcein labeling (green) (scale: $100 \mu \mathrm{m}$ ); (D) mineral apposition rate (MAR; $\mu \mathrm{m} /$ day); (E) bone formation rate (BFR/BS; $\mu \mathrm{m}^{3} / \mu \mathrm{m}^{2} /$ day); (F) osteocyte number per bone area (Ot.N/B.Ar; $\mathrm{mm}^{-2}$ ); (G) representative images of tartrate-resistant acid phosphatase (TRAP) staining for osteoclasts (purple) (scale: $500 \mu \mathrm{m}$ ); (H) osteoclast surface per bone surface (Oc.S/BS; $\%)$; and (I) osteoclast number per bone parameter (Oc.N/B.Pm; $\left.\mathrm{mm}^{-1}\right)(\mathrm{n}=4-6)$. Analysis of bone formation and resorption markers: (J) N-terminal propeptide of type I procollagen (PINP; ng/mL); and $(\mathbf{K})$ C-terminal telopeptides of type I collagen (CTX-I; ng/mL) $(n=4-6)$. Data are represented as box and whisker plots with the minimum to the maximum as well as superimposing all of the data points. Statistical differences between two groups were determined by one-way ANOVA and Tukey's test. ${ }^{*} p<0.05 ;{ }^{* *} p<0.01 ;{ }^{* *} p<0.001$, ns: no significance.

These results suggested that the rescue of GC-mediated bone loss in the combinatorial treatment group was due to a reduced osteoclastogenesis rather than an improved osteoblastogenesis.

Because osteoclastogenesis is indirectly regulated by osteoblasts via the expression of Rankl and Opg [69,70], we also investigated whether the Rankl/Opg axis is modulated in primary murine calvarial osteoblasts by Dex and siCdk5. Indeed, we observed a significant increase in the Rankl/Opg expression ratio upon Dex treatment, which was reduced by the co-treatment with siCdk5 (Figure S3), suggesting a possible mechanism of the reduction in GC-induced osteoclastogenesis upon Cdk5 inhibition in vivo. 
In conclusion, we demonstrated that GC-mediated bone loss is ameliorated by Cdk5 inhibition with roscovitine through a reduction in osteoclastogenesis.

\subsection{Cdk5 Inhibition Does Not Reverse GC-Mediated Impaired Fracture Healing}

To investigate GC-mediated impaired fracture healing under roscovitine treatment, we performed an open femur osteotomy, implanted a sham or Pred pellet and treated the mice with either a vehicle or roscovitine for 14 days (Figure $4 \mathrm{~A}$ ). Our results showed that after 14 days, a time point of extensive endochondral bone formation in murine fracture healing, the Pred treatment decreased the callus size and the bone area in the fracture callus, which were not reversed by the combinatorial treatment with roscovitine (Figure 4B-D). In addition, we did not observe any changes in cartilage or soft tissue areas upon Pred treatment alone or in combination with roscovitine (Figure $4 \mathrm{~B}, \mathrm{E}, \mathrm{F}$ ).

A

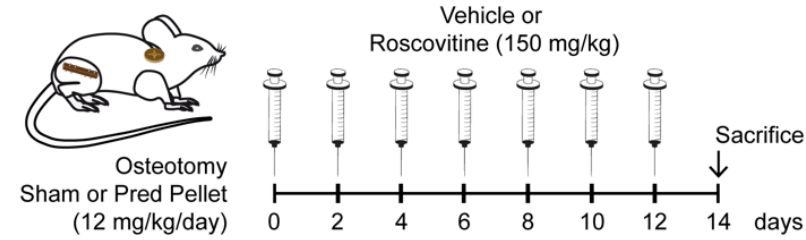

B

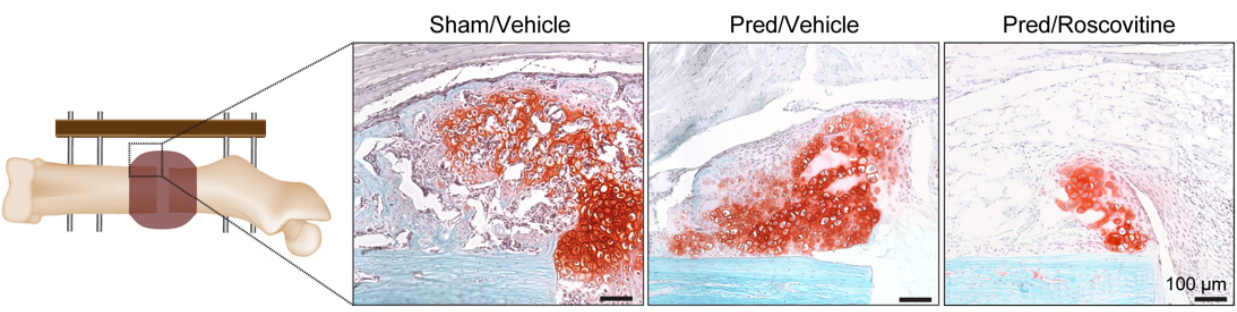

C

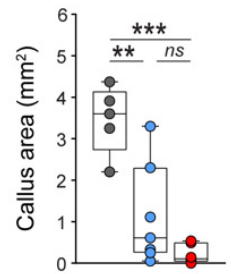

O Sham/Vehicle

D

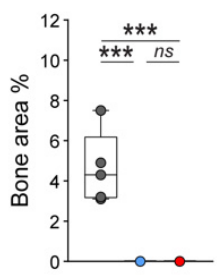

O Pred/Vehicle

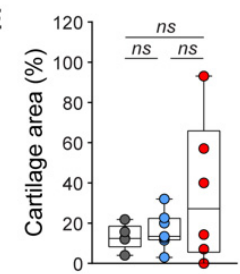

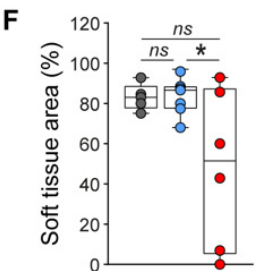

Figure 4. GC-mediated delayed fracture healing is not reversed by Cdk5 inhibition with roscovitine during soft callus formation. (A) Experimental setup for the osteotomy and implantation of a sham or Pred pellet, followed by treatment with a vehicle or roscovitine (i.p.; $150 \mathrm{mg} / \mathrm{kg}$; every second day) for 14 days, to evaluate soft callus formation. (B) Representative images of Safranin O/Fast Green staining of the fracture callus after different treatments (scale: $100 \mu \mathrm{m}$ ). The following parameters were calculated: (C) callus area $\left(\mathrm{mm}^{2}\right) ;(\mathbf{D})$ bone area (\%); (E) cartilage area (\%); and (F) soft tissue area $(\%)(n=5-7)$. Data are represented as box and whisker plots with the minimum to maximum as well as superimposing all of the data points. Statistical differences between two groups were determined by one-way ANOVA and Tukey's test. ${ }^{*} p<0.05 ;{ }^{* *} p<0.01$; ${ }^{* * *} p<0.001$, ns: no significance.

At a later healing stage of 23 days, the Pred treatment (Figure 5A) resulted in significantly impaired hard callus formation, as shown by a greatly reduced BV/TV and bending stiffness, which was not reversed by the combinative treatment with roscovitine (Figure 5B-D). These findings were further confirmed by the histological evaluation. While the callus area was not significantly affected, the bone area was significantly reduced in the Pred-treated mice compared to the control group. The co-treatment with Pred and roscovitine significantly reduced both the callus size and the bone content (Figure 5E-G), while the cartilage and soft tissue areas remained unaffected by the treatments (Figure $5 \mathrm{E}, \mathrm{H}, \mathrm{I}$ ). The Pred treatment significantly decreased the osteoblast number and surface, whereas the 
osteoclast number and surface were significantly increased in the newly formed bone of the fracture callus (Figure 5J-M). In the combinatorial treatment, the bone formation in the callus was abrogated, and no osteoblasts and osteoclasts were present (Figure 5G,J-M).

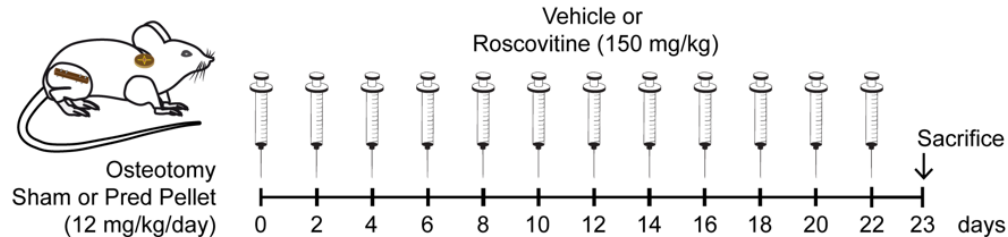

B

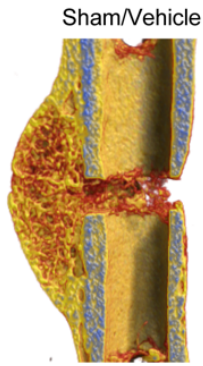

Pred/Vehicle

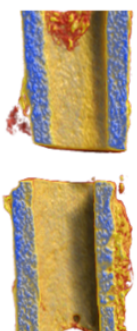

Pred/Roscovitine

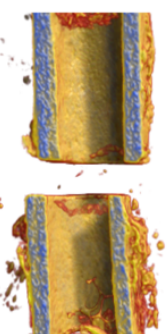

C

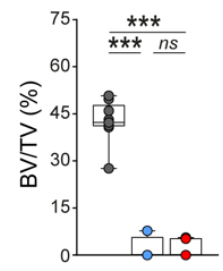

D

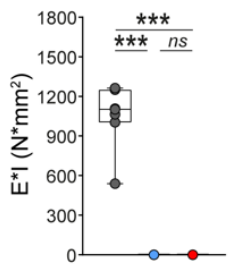

E

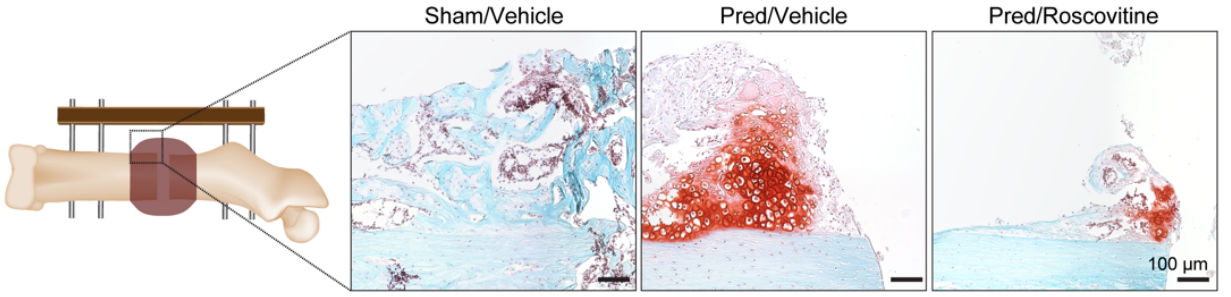

O Sham/Vehicle OPred/Vehicle

F

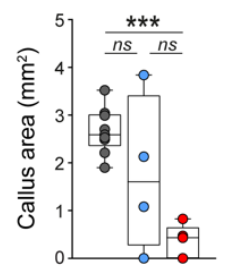

$\mathbf{J}$

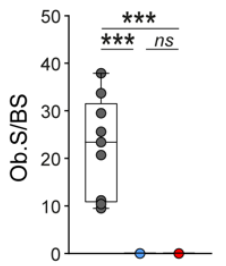

G

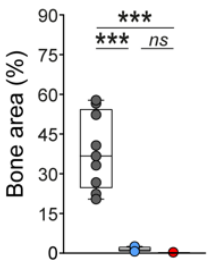

K

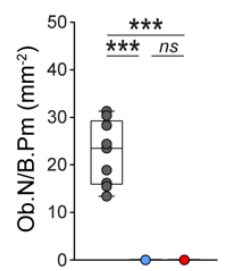

H

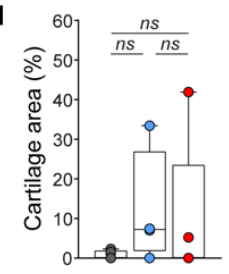

L

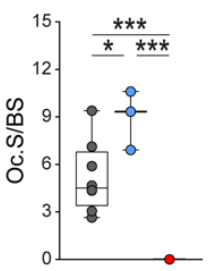

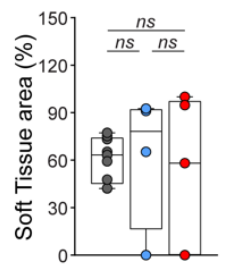

M

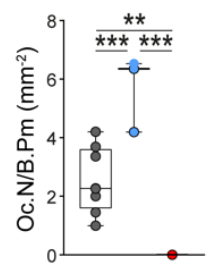

Figure 5. GC treatment delays fracture healing through decreased osteoblastogenesis, which could not be rescued by roscovitine application. (A) Experimental setup for the osteotomy and implantation of a sham or Pred pellet, followed by treatment with a vehicle or roscovitine (i.p.; $150 \mathrm{mg} / \mathrm{kg}$; every second day) for 23 days, to evaluate hard callus formation. (B) Representative $\mu \mathrm{CT}$ images of fractured femurs from different treatments. The calculated parameters include the following: (C) bone volume fraction (BV/TV; \%) ( $n=4-9)$; and (D) bending stiffness ( $\left.E^{*} \mathrm{I} ; \mathrm{N} / \mathrm{mm}^{2}\right)(\mathrm{n}=4-7)$. (E) Representative images of the Safranin O/Fast Green staining of fracture callus after different treatments (scale: $100 \mu \mathrm{m})$. The following parameters were calculated: $(\mathbf{F})$ callus area $\left(\mathrm{mm}^{2}\right) ;(\mathbf{G})$ bone area (\%); (H) cartilage area (\%); (I) soft tissue area (\%); (J) osteoblast surface per bone surface (Ob.S/BS; \%); 
(K) osteoblast number per bone parameter $\left(\right.$ Ob.N/B.Pm; $\left.\mathrm{mm}^{-1}\right)(\mathrm{n}=4-9)$; $(\mathbf{L})$ osteoclast surface per bone surface (Oc.S/BS; \%); and (M), osteoclast number per bone parameter (Oc.N/B.Pm; mm $^{-1}$ ) $(n=4-8)$. Data are represented as box and whisker plots with the minimum to the maximum as well as superimposing all of the data points. Statistical differences between two groups were determined by one-way ANOVA and Tukey's test. ${ }^{*} p<0.05$; ${ }^{* *} p<0.01$; ${ }^{* * *} p<0.001$, ns: no significance.

In summary, we conclude that Cdk5 inhibition with roscovitine was unable to ameliorate the deleterious effects of GCs on bone fracture healing.

\section{Discussion}

Common side effects of GC treatment in the context of bone biology are GIO and impaired fracture healing $[1,13,27,28,71]$. Recently, we identified Cdk5 as a promising target to increase osteoblast differentiation and bone mass and improve fracture healing in skeletally healthy mice [53]. Here, we assessed whether the pharmacological inhibition of Cdk5 with roscovitine has the potential to ameliorate the adverse effects of GCs on bone and in impairing fracture healing. Indeed, Cdk5 inhibition rescued GC-induced skeletal bone loss through reduced osteoclastogenesis, however; it did not reverse GC-mediated compromised fracture healing.

Cdk5 is known to be involved in neuronal differentiation [72], and its aberrant activity contributes to the pathogenesis of neurodegenerative disorders, including amyotrophic lateral sclerosis and Huntington's, Alzheimer's, and Parkinson's diseases [50-52]. Additionally, there is growing evidence that C $\mathrm{dk} 5$ plays a role in T cell activation and cancer biology [73-75]. Recently, our group reported for the first time a crucial role of Cdk5 in bone biology [53]. Cdk5 strongly suppresses osteoblast differentiation through the mitogen-activated protein kinase pathway, and Cdk5 inhibition with the small-molecule inhibitor, roscovitine, induces osteoanabolic effects on bone mass and formation during fracture healing in skeletally healthy mice [53]. On the basis of these findings, we here determined whether Cdk5 inhibition has the potential to counteract GC-induced bone loss and impaired fracture healing.

It is well established that high-dose GC treatment inhibits osteoblast differentiation and mineralization in vitro and reduces trabecular and cortical bone mass in vivo $[1,3,10,16,17,19,67,68,76-79]$. This GC-mediated bone loss phenotype is mainly attributed to decreased osteoblastogenesis and osteocyte number that subsequently reduce bone formation, but also to increased osteoclastogenesis, which consequently enhances bone resorption $[10,19,76-78,80]$. In the present study, we confirmed the negative effects of high-dose GCs both in vitro and in vivo.

Our in vitro results showed that Cdk5 deletion or inhibition with roscovitine not only completely abolished the GC-mediated detrimental effects on osteoblast differentiation, but even increased osteoblast activity compared to untreated cells. This effect can be explained by a possible crosstalk between GC- and Cdk5-regulated pathways. For example, it is well-known that the extracellular signal-regulated kinase (Erk1/2) pathway is crucial for osteoblastogenesis [81], and exogenous GCs have been shown to inhibit this pathway [82]. Moreover, we recently reported that Cdk5 depletion in osteoblasts activates the Erk1/2 pathway [53], suggesting one of the possible mechanisms through which Cdk5 depletion counteracts the GC-mediated inhibition of the Erk1/2 pathway and consequently the osteoblast differentiation.

Importantly, our in vivo results demonstrated that Cdk5 inhibition with roscovitine ameliorated GC-mediated bone loss in mice. Of note, we here observed that Cdk5 inhibition prevented GC-mediated bone loss through a reduction of osteoclastogenesis rather than by promoting osteoblastogenesis and new bone formation. This is in contrast to our previous study with skeletally healthy mice, where we observed a significant osteoanabolic effect of Cdk5 inhibition caused by the induction of osteoblastogenesis [53]. Although this was unexpected, similar findings have been reported with other osteoblast-stimulating drugs under GC therapy. For example, the osteoanabolic effect of intermittent PTH and 
abaloparatide treatment was blunted by high-dose GCs [77,83]. Obviously, even if our in vitro results implicate a rescue through osteoblastogenesis, osteoblast function cannot completely be reversed by Cdk5 inhibition in the presence of GCs in vivo.

The reduction of osteoclastogenesis observed in GC-treated mice by Cdk5 inhibition could be explained by the modulation of the ratio of Rankl/Opg expression. Generally, osteoblasts proportionately express Rankl, which regulates the differentiation of precursor cells into multinucleated osteoclasts, and $O p g$, a decoy receptor for Rankl that protects the skeleton from excessive bone resorption [84-87]. However, supraphysiological GC doses are known to modulate the Rankl/Opg axis by upregulating Rankl expression levels and downregulating Opg expression levels, which consequently promotes osteoclastogenesis and eventually bone resorption $[3,19,78]$. To this end, we here observed a similar effect on the Rankl/Opg axis after treating primary murine calvarial osteoblasts with Dex. Interestingly, $C d k 5$ deletion reversed this GC-mediated effect on the Rankl/Opg ratio, suggesting a possible crosstalk between osteoblasts and osteoclasts, which eventually reduces GC-mediated increased osteoclastogenesis in vivo.

Bone fracture healing is a multifactorial process, which involves overlapping phases of inflammation, soft- and hard-callus formation, during which bone is generated by intramembranous and endochondral ossification, and the remodeling of the initially formed woven bone until the original bone structure is restored [88-90]. Disruption at any stage of this highly complex healing cascade can delay or even prevent the healing success $[20,88]$. GCs have a strong effect on many cell types participating in fracture healing, including immune and mesenchymal cells [21,22], and long-term administration is proposed to induce detrimental effects on all stages of fracture repair $[27,28]$. To determine the role of Cdk5 in GC-mediated impaired fracture healing, we used the same femur fracture model as in our recent study, where we observed osteoanabolic effects of Cdk5 inhibition and improved fracture healing in healthy mice [53]. As expected from the literature, the healing process was considerably impaired upon GC treatment, both at the early and late phases, as indicated by the significantly reduced bone fraction and osteoblast number and activity in the fracture callus $[27,28]$. Cdk5 inhibition was not able to reverse these negative effects. This supports our observation that in the GIO model, Cdk5 inhibition rescued increased osteoclastogenesis rather than improved osteoblastogenesis. However, there could be additional reasons for the failure of roscovitine to improve GC-induced impaired bone healing. For example, because Cdk5 is known to regulate inflammation [91-94], its inhibition could possibly exacerbate GC effects on the immune response upon fracture, which is essential for downstream regenerative processes $[22,88,89,95]$. Another possible reason could be that Cdk5 inhibition or high-dose GCs adversely affects angiogenesis [16,96-101], a process that is essential for uneventful fracture healing $[89,95]$.

\section{Conclusions}

In conclusion, our results demonstrated that, even if the pharmacological inhibition of Cdk5 with roscovitine did not reverse GC-induced compromised fracture healing in mice, it ameliorated GC-mediated bone loss in the skeleton. Together with our previous data [53], this indicates that Cdk5 could be a potential therapeutic target to treat GIO. However, further studies are necessary to elucidate the role of Cdk5 in bone, particularly in inflammatory bone disorders.

Supplementary Materials: The following supporting information can be downloaded at: https: / / www.mdpi.com/article/10.3390/biomedicines10020404/s1, Figure S1: Complete western blot related to Figure 1; Figure S2: Inhibition of Cdk5 with roscovitine alleviates GC-mediated bone loss by reducing osteoclastogenesis; Figure S3: Cdk5 siRNA knockdown modulates the GC-mediated Rankl/Opg ratio. 
Author Contributions: Conceptualization: B.T.K., A.I., J.T. and M.A.; methodology: B.T.K., L.S., S.V., M.H.-L. and M.A.; formal analysis: B.T.K., L.S., S.V., S.L., A.-K.D. and M.A.; data curation: B.T.K. and M.A.; writing—original draft preparation: B.T.K., A.I., J.T. and M.A.; writing—review and editing: B.T.K., A.I., J.T. and M.A.; visualization: B.T.K. and M.A.; supervision: A.I., J.T. and M.A.; project administration: A.I., J.T. and M.A.; funding acquisition: A.I. and J.T. All authors have read and agreed to the published version of the manuscript.

Funding: This research was funded by a grant from the DFG in the framework of Collaborative Research Center CRC1149 "Danger Response, Disturbance Factors and Regenerative Potential after Trauma" (No. 251293561-CRC 1149, INST 40/492-1, and INST 40/492-2) and Tu220/14-1 ("A novel function of cyclin-dependent kinase $5(\mathrm{Cdk} 5)$ in bone integrity-a potential therapeutic target to treat osteoporosis").

Institutional Review Board Statement: The animal experiments were approved by the local ethical committee, Regierungspräsidium Tübingen, Baden-Württemberg, Germany (No.: 1245/1402).

Data Availability Statement: Not applicable.

Acknowledgments: We are grateful to acknowledge the animal facility at Ulm University, in particular the expert assistance of B. Widmann. We thank U. Burret for ordering the mice, U. Kelp, K. Karremann, T. Hieber, A. Boehmler, and Y. Aydogdu, for their assistance with the sample preparation for bone histomorphometry and I. Baum for the preparation of roscovitine for in vivo treatment.

Conflicts of Interest: The authors declare no conflict of interest.

\section{References}

1. Hartmann, K.; Koenen, M.; Schauer, S.; Wittig-Blaich, S.; Ahmad, M.; Baschant, U.; Tuckermann, J.P. Molecular Actions of Glucocorticoids in Cartilage and Bone During Health, Disease, and Steroid Therapy. Physiol. Rev. 2016, 96, 409-447. [CrossRef] [PubMed]

2. Agusti, A.; Fabbri, L.M.; Singh, D.; Vestbo, J.; Celli, B.; Franssen, F.M.E.; Rabe, K.F.; Papi, A. Inhaled corticosteroids in COPD: Friend or foe? Eur. Respir. J. 2018, 52, 1801219. [CrossRef]

3. Ahmad, M.; Hachemi, Y.; Paxian, K.; Mengele, F.; Koenen, M.; Tuckermann, J. A Jack of All Trades: Impact of Glucocorticoids on Cellular Cross-Talk in Osteoimmunology. Front. Immunol. 2019, 10, 2460. [CrossRef] [PubMed]

4. Bruscoli, S.; Febo, M.; Riccardi, C.; Migliorati, G. Glucocorticoid Therapy in Inflammatory Bowel Disease: Mechanisms and Clinical Practice. Front. Immunol. 2021, 12, 691480. [CrossRef]

5. Buttgereit, F.; Burmester, G.R.; Lipworth, B.J. Optimised glucocorticoid therapy: The sharpening of an old spear. Lancet 2005, 365, 801-803. [CrossRef]

6. Mazziotti, G.; Angeli, A.; Bilezikian, J.P.; Canalis, E.; Giustina, A. Glucocorticoid-induced osteoporosis: An update. Trends Endocrinol. Metab. TEM 2006, 17, 144-149. [CrossRef]

7. Mazziotti, G.; Giustina, A.; Canalis, E.; Bilezikian, J.P. Treatment of glucocorticoid-induced osteoporsis. Ther. Adv. Musculoskelet. Dis. 2009, 1, 27-34. [CrossRef] [PubMed]

8. Saag, K.G.; Koehnke, R.; Caldwell, J.R.; Brasington, R.; Burmeister, L.F.; Zimmerman, B.; Kohler, J.A.; Furst, D.E. Low dose long-term corticosteroid therapy in rheumatoid arthritis: An analysis of serious adverse events. Am. J. Med. 1994, 96, 115-123. [CrossRef]

9. Adami, G.; Saag, K.G. Glucocorticoid-induced osteoporosis update. Curr. Opin. Rheumatol. 2019, 31, 388-393. [CrossRef]

10. Rauch, A.; Seitz, S.; Baschant, U.; Schilling, A.F.; Illing, A.; Stride, B.; Kirilov, M.; Mandic, V.; Takacz, A.; Schmidt-Ullrich, R.; et al. Glucocorticoids suppress bone formation by attenuating osteoblast differentiation via the monomeric glucocorticoid receptor. Cell Metab. 2010, 11, 517-531. [CrossRef]

11. Hofbauer, L.C.; Zeitz, U.; Schoppet, M.; Skalicky, M.; Schuler, C.; Stolina, M.; Kostenuik, P.J.; Erben, R.G. Prevention of glucocorticoid-induced bone loss in mice by inhibition of RANKL. Arthritis Rheum. 2009, 60, 1427-1437. [CrossRef] [PubMed]

12. Ishida, Y.; Heersche, J.N. Glucocorticoid-induced osteoporosis: Both in vivo and in vitro concentrations of glucocorticoids higher than physiological levels attenuate osteoblast differentiation. J. Bone Miner. Res. 1998, 13, 1822-1826. [CrossRef] [PubMed]

13. Canalis, E.; Mazziotti, G.; Giustina, A.; Bilezikian, J.P. Glucocorticoid-induced osteoporosis: Pathophysiology and therapy. Osteoporos. Int. 2007, 18, 1319-1328. [CrossRef] [PubMed]

14. Frenkel, B.; White, W.; Tuckermann, J. Glucocorticoid-induced osteoporosis. In Glucocorticoid Signaling; Springer: Berlin/Heidelberg, Germany, 2015; pp. 179-215.

15. Weinstein, R.S.; Jilka, R.L.; Parfitt, A.M.; Manolagas, S.C. Inhibition of osteoblastogenesis and promotion of apoptosis of osteoblasts and osteocytes by glucocorticoids. Potential mechanisms of their deleterious effects on bone. J. Clin. Investig. 1998, 102, 274-282. [CrossRef] [PubMed] 
16. Weinstein, R.S.; Hogan, E.A.; Borrelli, M.J.; Liachenko, S.; O’Brien, C.A.; Manolagas, S.C. The Pathophysiological Sequence of Glucocorticoid-Induced Osteonecrosis of the Femoral Head in Male Mice. Endocrinology 2017, 158, 3817-3831. [CrossRef] [PubMed]

17. Manolagas, S.C. Steroids and osteoporosis: The quest for mechanisms. J. Clin. Investig. 2013, 123, 1919-1921. [CrossRef] [PubMed]

18. Humphrey, E.L.; Williams, J.H.; Davie, M.W.; Marshall, M.J. Effects of dissociated glucocorticoids on OPG and RANKL in osteoblastic cells. Bone 2006, 38, 652-661. [CrossRef] [PubMed]

19. Piemontese, M.; Xiong, J.; Fujiwara, Y.; Thostenson, J.D.; O’Brien, C.A. Cortical bone loss caused by glucocorticoid excess requires RANKL production by osteocytes and is associated with reduced OPG expression in mice. Am. J. Physiol. Endocrinol. Metab. 2016, 311, E587-E593. [CrossRef]

20. Wildemann, B.; Ignatius, A.; Leung, F.; Taitsman, L.A.; Smith, R.M.; Pesántez, R.; Stoddart, M.J.; Richards, R.G.; Jupiter, J.B. Non-union bone fractures. Nat. Rev. Dis. Primers 2021, 7, 57. [CrossRef] [PubMed]

21. Rapp, A.E.; Hachemi, Y.; Kemmler, J.; Koenen, M.; Tuckermann, J.; Ignatius, A. Induced global deletion of glucocorticoid receptor impairs fracture healing. FASEB J. Off. Publ. Fed. Am. Soc. Exp. Biol. 2018, 32, 2235-2245. [CrossRef] [PubMed]

22. Hachemi, Y.; Rapp, A.E.; Picke, A.K.; Weidinger, G.; Ignatius, A.; Tuckermann, J. Molecular mechanisms of glucocorticoids on skeleton and bone regeneration after fracture. J. Mol. Endocrinol. 2018, 61, R75-R90. [CrossRef] [PubMed]

23. Hachemi, Y.; Rapp, A.E.; Lee, S.; Dorn, A.K.; Krüger, B.T.; Kaiser, K.; Ignatius, A.; Tuckermann, J. Intact Glucocorticoid Receptor Dimerization Is Deleterious in Trauma-Induced Impaired Fracture Healing. Front. Immunol. 2020, 11, 628287. [CrossRef] [PubMed]

24. Waters, R.V.; Gamradt, S.C.; Asnis, P.; Vickery, B.H.; Avnur, Z.; Hill, E.; Bostrom, M. Systemic corticosteroids inhibit bone healing in a rabbit ulnar osteotomy model. Acta Orthop. Scand. 2000, 71, 316-321. [CrossRef] [PubMed]

25. Lyritis, G.; Papadopoulou, Z.; Nikiforidis, P.; Batrinos, M.; Varonos, D. Effect of cortisone and an anabolic steroid upon plasma hydroxyproline during fracture healing in rabbits. Acta Orthop. Scand. 1975, 46, 25-30. [CrossRef]

26. Newman, R.J.; Francis, M.J.; Duthie, R.B. Nuclear magnetic resonance studies of experimentally induced delayed fracture union Clin. Orthop. Relat. Res. 1987, 216, 253-261. [CrossRef]

27. Liu, Y.Z.; Akhter, M.P.; Gao, X.; Wang, X.Y.; Wang, X.B.; Zhao, G.; Wei, X.; Wu, H.J.; Chen, H.; Wang, D.; et al. Glucocorticoidinduced delayed fracture healing and impaired bone biomechanical properties in mice. Clin. Interv. Aging 2018, 13, 1465-1474. [CrossRef]

28. Sandberg, O.H.; Aspenberg, P. Glucocorticoids inhibit shaft fracture healing but not metaphyseal bone regeneration under stable mechanical conditions. Bone Jt. Res. 2015, 4, 170-175. [CrossRef]

29. Allen, C.S.; Yeung, J.H.; Vandermeer, B.; Homik, J. Bisphosphonates for steroid-induced osteoporosis. Cochrane Database Syst. Rev. 2016, 10, Cd001347. [CrossRef] [PubMed]

30. Bultink, I.E.; Baden, M.; Lems, W.F. Glucocorticoid-induced osteoporosis: An update on current pharmacotherapy and future directions. Expert Opin. Pharm. 2013, 14, 185-197. [CrossRef]

31. Saag, K.G.; Shane, E.; Boonen, S.; Marin, F.; Donley, D.W.; Taylor, K.A.; Dalsky, G.P.; Marcus, R. Teriparatide or alendronate in glucocorticoid-induced osteoporosis. N. Engl. J. Med. 2007, 357, 2028-2039. [CrossRef] [PubMed]

32. Saag, K.G.; Wagman, R.B.; Geusens, P.; Adachi, J.D.; Messina, O.D.; Emkey, R.; Chapurlat, R.; Wang, A.; Pannacciulli, N.; Lems, W.F. Denosumab versus risedronate in glucocorticoid-induced osteoporosis: A multicentre, randomised, double-blind, active-controlled, double-dummy, non-inferiority study. Lancet Diabetes Endocrinol. 2018, 6, 445-454. [CrossRef]

33. Reginster, J.Y.; Kuntz, D.; Verdickt, W.; Wouters, M.; Guillevin, L.; Menkès, C.J.; Nielsen, K. Prophylactic use of alfacalcidol in corticosteroid-induced osteoporosis. Osteoporos. Int. 1999, 9, 75-81. [CrossRef] [PubMed]

34. Amin, S.; LaValley, M.P.; Simms, R.W.; Felson, D.T. The role of vitamin D in corticosteroid-induced osteoporosis: A meta-analytic approach. Arthritis Rheum. 1999, 42, 1740-1751. [CrossRef]

35. Homik, J.; Suarez-Almazor, M.E.; Shea, B.; Cranney, A.; Wells, G.; Tugwell, P. Calcium and vitamin D for corticosteroid-induced osteoporosis. Cochrane Database Syst. Rev. 2000, 1998, Cd000952. [CrossRef]

36. Raterman, H.G.; Bultink, I.E.M.; Lems, W.F. Current Treatments and New Developments in the Management of Glucocorticoidinduced Osteoporosis. Drugs 2019, 79, 1065-1087. [CrossRef]

37. Lane, N.E.; Sanchez, S.; Modin, G.W.; Genant, H.K.; Pierini, E.; Arnaud, C.D. Parathyroid hormone treatment can reverse corticosteroid-induced osteoporosis. Results of a randomized controlled clinical trial. J. Clin. Investig. 1998, 102, 1627-1633. [CrossRef]

38. Amiche, M.A.; Lévesque, L.E.; Gomes, T.; Adachi, J.D.; Cadarette, S.M. Effectiveness of Oral Bisphosphonates in Reducing Fracture Risk Among Oral Glucocorticoid Users: Three Matched Cohort Analyses. J. Bone Miner. Res. 2018, 33, 419-429. [CrossRef] [PubMed]

39. Murphy, D.R.; Smolen, L.J.; Klein, T.M.; Klein, R.W. The cost effectiveness of teriparatide as a first-line treatment for glucocorticoidinduced and postmenopausal osteoporosis patients in Sweden. BMC Musculoskelet. Disord. 2012, 13, 213. [CrossRef] [PubMed]

40. Hsu, E.; Nanes, M. Advances in treatment of glucocorticoid-induced osteoporosis. Curr. Opin. Endocrinol. Diabetes Obes. 2017, 24, 411-417. [CrossRef]

41. Kawano, T.; Miyakoshi, N.; Kasukawa, Y.; Hongo, M.; Tsuchie, H.; Sato, C.; Fujii, M.; Suzuki, M.; Akagawa, M.; Ono, Y.; et al Effects of combined therapy of alendronate and low-intensity pulsed ultrasound on metaphyseal bone repair after osteotomy in the proximal tibia of glucocorticoid-induced osteopenia rats. Osteoporos Sarcopenia 2017, 3, 185-191. [CrossRef] [PubMed] 
42. Doyon, A.R.; Ferries, I.K.; Li, J. Glucocorticoid attenuates the anabolic effects of parathyroid hormone on fracture repair. Calcif. Tissue Int. 2010, 87, 68-76. [CrossRef] [PubMed]

43. Kennel, K.A.; Drake, M.T. Adverse effects of bisphosphonates: Implications for osteoporosis management. Mayo Clin. Proc. 2009, 84, 632-637, quiz 638. [CrossRef]

44. Vahle, J.L.; Long, G.G.; Sandusky, G.; Westmore, M.; Ma, Y.L.; Sato, M. Bone neoplasms in F344 rats given teriparatide [rhPTH(134)] are dependent on duration of treatment and dose. Toxicol. Pathol. 2004, 32, 426-438. [CrossRef] [PubMed]

45. Miller, P.D. Safety of parathyroid hormone for the treatment of osteoporosis. Curr. Osteoporos. Rep. 2008, 6, 12-16. [CrossRef] [PubMed]

46. Otto, S.; Pautke, C.; Van den Wyngaert, T.; Niepel, D.; Schiødt, M. Medication-related osteonecrosis of the jaw: Prevention, diagnosis and management in patients with cancer and bone metastases. Cancer Treat. Rev. 2018, 69, 177-187. [CrossRef]

47. Hildebrand, G.K.; Kasi, A. Denosumab. In StatPearls; StatPearls Publishing: Treasure Island, FL, USA, 2021.

48. Dhavan, R.; Tsai, L.H. A decade of CDK5. Nat. Rev. Mol. Cell Biol. 2001, 2, 749-759. [CrossRef]

49. Chang, K.H.; Vincent, F.; Shah, K. Deregulated Cdk5 triggers aberrant activation of cell cycle kinases and phosphatases inducing neuronal death. J. Cell Sci. 2012, 125, 5124-5137. [CrossRef]

50. Nguyen, M.D.; Julien, J.P. Cyclin-dependent kinase 5 in amyotrophic lateral sclerosis. Neurosignals 2003, 12, 215-220. [CrossRef] [PubMed]

51. Paoletti, P.; Vila, I.; Rife, M.; Lizcano, J.M.; Alberch, J.; Gines, S. Dopaminergic and glutamatergic signaling crosstalk in Huntington's disease neurodegeneration: The role of p25/cyclin-dependent kinase 5. J. Neurosci. 2008, 28, 10090-10101. [CrossRef]

52. Lopes, J.P.; Agostinho, P. Cdk5: Multitasking between physiological and pathological conditions. Prog. Neurobiol. 2011, 94, 49-63. [CrossRef]

53. Ahmad, M.; Krüger, B.T.; Kroll, T.; Vettorazzi, S.; Dorn, A.-K.; Mengele, F.; Lee, S.; Nandi, S.; Yilmaz, D.; Stolz, M.; et al. Inhibition of Cdk5 increases osteoblast differentiation, bone mass and improves fracture healing. Bone Res. 2021. [CrossRef]

54. Ahmad, M.; Kroll, T.; Jakob, J.; Rauch, A.; Ploubidou, A.; Tuckermann, J. Cell-based RNAi screening and high-content analysis in primary calvarian osteoblasts applied to identification of osteoblast differentiation regulators. Sci. Rep. 2018, 8, 14045. [CrossRef]

55. Jonason, J.H.; O'Keefe, R.J. Isolation and culture of neonatal mouse calvarial osteoblasts. Methods Mol. Biol. 2014, 1130, 295-305. [CrossRef] [PubMed]

56. Gregory, C.A.; Gunn, W.G.; Peister, A.; Prockop, D.J. An Alizarin red-based assay of mineralization by adherent cells in culture: Comparison with cetylpyridinium chloride extraction. Anal. Biochem. 2004, 329, 77-84. [CrossRef]

57. Schindelin, J.; Arganda-Carreras, I.; Frise, E.; Kaynig, V.; Longair, M.; Pietzsch, T.; Preibisch, S.; Rueden, C.; Saalfeld, S.; Schmid, B.; et al. Fiji: An open-source platform for biological-image analysis. Nat. Methods 2012, 9, 676-682. [CrossRef] [PubMed]

58. Thiele, S.; Baschant, U.; Rauch, A.; Rauner, M. Instructions for producing a mouse model of glucocorticoid-induced osteoporosis. BoneKEy Rep. 2014, 3, 552. [CrossRef] [PubMed]

59. Röntgen, V.; Blakytny, R.; Matthys, R.; Landauer, M.; Wehner, T.; Göckelmann, M.; Jermendy, P.; Amling, M.; Schinke, T.; Claes, L.; et al. Fracture healing in mice under controlled rigid and flexible conditions using an adjustable external fixator. J. Orthop. Res. Off. Publ. Orthop. Res. Soc. 2010, 28, 1456-1462. [CrossRef] [PubMed]

60. Morgan, E.F.; Mason, Z.D.; Chien, K.B.; Pfeiffer, A.J.; Barnes, G.L.; Einhorn, T.A.; Gerstenfeld, L.C. Micro-computed tomography assessment of fracture healing: Relationships among callus structure, composition, and mechanical function. Bone 2009, 44 335-344. [CrossRef]

61. Bouxsein, M.L.; Boyd, S.K.; Christiansen, B.A.; Guldberg, R.E.; Jepsen, K.J.; Muller, R. Guidelines for assessment of bone microstructure in rodents using micro-computed tomography. J. Bone Miner. Res. 2010, 25, 1468-1486. [CrossRef]

62. Najafova, Z.; Liu, P.; Wegwitz, F.; Ahmad, M.; Tamon, L.; Kosinsky, R.L.; Xie, W.; Johnsen, S.A.; Tuckermann, J. RNF40 exerts stage-dependent functions in differentiating osteoblasts and is essential for bone cell crosstalk. Cell Death Differ. 2020. [CrossRef]

63. Liu, P.; Lee, S.; Knoll, J.; Rauch, A.; Ostermay, S.; Luther, J.; Malkusch, N.; Lerner, U.H.; Zaiss, M.M.; Neven, M.; et al. Loss of menin in osteoblast lineage affects osteocyte-osteoclast crosstalk causing osteoporosis. Cell Death Differ. 2017, 24, 672-682. [CrossRef] [PubMed]

64. Parfitt, A.M.; Drezner, M.K.; Glorieux, F.H.; Kanis, J.A.; Malluche, H.; Meunier, P.J.; Ott, S.M.; Recker, R.R. Bone histomorphometry: Standardization of nomenclature, symbols, and units. Report of the ASBMR Histomorphometry Nomenclature Committee. $J$. Bone Miner. Res. 1987, 2, 595-610. [CrossRef]

65. Dempster, D.W.; Compston, J.E.; Drezner, M.K.; Glorieux, F.H.; Kanis, J.A.; Malluche, H.; Meunier, P.J.; Ott, S.M.; Recker, R.R.; Parfitt, A.M. Standardized nomenclature, symbols, and units for bone histomorphometry: A 2012 update of the report of the ASBMR Histomorphometry Nomenclature Committee. J. Bone Miner. Res. 2013, 28, 2-17. [CrossRef]

66. Amling, M.; Priemel, M.; Holzmann, T.; Chapin, K.; Rueger, J.M.; Baron, R.; Demay, M.B. Rescue of the skeletal phenotype of vitamin $\mathrm{D}$ receptor-ablated mice in the setting of normal mineral ion homeostasis: Formal histomorphometric and biomechanical analyses. Endocrinology 1999, 140, 4982-4987. [CrossRef]

67. Li, J.; Zhang, N.; Huang, X.; Xu, J.; Fernandes, J.C.; Dai, K.; Zhang, X. Dexamethasone shifts bone marrow stromal cells from osteoblasts to adipocytes by C/EBPalpha promoter methylation. Cell Death Dis. 2013, 4, e832. [CrossRef] [PubMed]

68. Luppen, C.A.; Smith, E.; Spevak, L.; Boskey, A.L.; Frenkel, B. Bone morphogenetic protein-2 restores mineralization in glucocorticoid-inhibited MC3T3-E1 osteoblast cultures. J. Bone Miner. Res. 2003, 18, 1186-1197. [CrossRef] 
69. Martin, T.J.; Ng, K.W. Mechanisms by which cells of the osteoblast lineage control osteoclast formation and activity. J. Cell. Biochem. 1994, 56, 357-366. [CrossRef]

70. Thomas, G.P.; Baker, S.U.; Eisman, J.A.; Gardiner, E.M. Changing RANKL/OPG mRNA expression in differentiating murine primary osteoblasts. J. Endocrinol. 2001, 170, 451-460. [CrossRef]

71. Compston, J. Glucocorticoid-induced osteoporosis. Horm. Res. 2003, 60 (Suppl. 3), 77-79. [CrossRef]

72. Tsai, L.H.; Takahashi, T.; Caviness, V.S., Jr.; Harlow, E. Activity and expression pattern of cyclin-dependent kinase 5 in the embryonic mouse nervous system. Development 1993, 119, 1029-1040. [CrossRef] [PubMed]

73. Sharma, S.; Zhang, T.; Michowski, W.; Rebecca, V.W.; Xiao, M.; Ferretti, R.; Suski, J.M.; Bronson, R.T.; Paulo, J.A.; Frederick, D.; et al. Targeting the cyclin-dependent kinase 5 in metastatic melanoma. Proc. Natl. Acad. Sci. USA 2020, 117, 8001-8012. [CrossRef] [PubMed]

74. Dorand, R.D.; Nthale, J.; Myers, J.T.; Barkauskas, D.S.; Avril, S.; Chirieleison, S.M.; Pareek, T.K.; Abbott, D.W.; Stearns, D.S.; Letterio, J.J.; et al. Cdk5 disruption attenuates tumor PD-L1 expression and promotes antitumor immunity. Science 2016, 353, 399-403. [CrossRef]

75. Askew, D.; Pareek, T.K.; Eid, S.; Ganguly, S.; Tyler, M.; Huang, A.Y.; Letterio, J.J.; Cooke, K.R. Cyclin-dependent kinase 5 activity is required for allogeneic T-cell responses after hematopoietic cell transplantation in mice. Blood 2017, 129, 246-256. [CrossRef]

76. Ersek, A.; Santo, A.I.; Vattakuzhi, Y.; George, S.; Clark, A.R.; Horwood, N.J. Strain dependent differences in glucocorticoid-induced bone loss between C57BL/6J and CD-1 mice. Sci. Rep. 2016, 6, 36513. [CrossRef] [PubMed]

77. Brent, M.B.; Thomsen, J.S.; Brüel, A. Short-term glucocorticoid excess blunts abaloparatide-induced increase in femoral bone mass and strength in mice. Sci. Rep. 2021, 11, 12258. [CrossRef] [PubMed]

78. Thiele, S.; Ziegler, N.; Tsourdi, E.; De Bosscher, K.; Tuckermann, J.P.; Hofbauer, L.C.; Rauner, M. Selective glucocorticoid receptor modulation maintains bone mineral density in mice. J. Bone Miner. Res. 2012, 27, 2242-2250. [CrossRef]

79. Yao, W.; Cheng, Z.; Pham, A.; Busse, C.; Zimmermann, E.A.; Ritchie, R.O.; Lane, N.E. Glucocorticoid-induced bone loss in mice can be reversed by the actions of parathyroid hormone and risedronate on different pathways for bone formation and mineralization. Arthritis Rheum. 2008, 58, 3485-3497. [CrossRef]

80. Hildebrandt, S.; Baschant, U.; Thiele, S.; Tuckermann, J.; Hofbauer, L.C.; Rauner, M. Glucocorticoids suppress Wnt16 expression in osteoblasts in vitro and in vivo. Sci. Rep. 2018, 8, 8711. [CrossRef]

81. Matsushita, T.; Chan, Y.Y.; Kawanami, A.; Balmes, G.; Landreth, G.E.; Murakami, S. Extracellular signal-regulated kinase 1 (ERK1) and ERK2 play essential roles in osteoblast differentiation and in supporting osteoclastogenesis. Mol. Cell Biol. 2009, 29, 5843-5857. [CrossRef]

82. Kassel, O.; Sancono, A.; Kratzschmar, J.; Kreft, B.; Stassen, M.; Cato, A.C. Glucocorticoids inhibit MAP kinase via increased expression and decreased degradation of MKP-1. EMBO J. 2001, 20, 7108-7116. [CrossRef]

83. Postnov, A.; De Schutter, T.; Sijbers, J.; Karperien, M.; De Clerck, N. Glucocorticoid-induced osteoporosis in growing mice is not prevented by simultaneous intermittent PTH treatment. Calcif. Tissue Int. 2009, 85, 530-537. [CrossRef]

84. Boyce, B.F.; Xing, L. The RANKL/RANK/OPG pathway. Curr. Osteoporos. Rep. 2007, 5, 98-104. [CrossRef]

85. Boyce, B.F.; Xing, L. Functions of RANKL/RANK/OPG in bone modeling and remodeling. Arch. Biochem. Biophys. 2008, 473, 139-146. [CrossRef] [PubMed]

86. Udagawa, N.; Takahashi, N.; Yasuda, H.; Mizuno, A.; Itoh, K.; Ueno, Y.; Shinki, T.; Gillespie, M.T.; Martin, T.J.; Higashio, K.; et al. Osteoprotegerin produced by osteoblasts is an important regulator in osteoclast development and function. Endocrinology 2000 141, 3478-3484. [CrossRef] [PubMed]

87. Baron, R.; Chakraborty, M.; Chatterjee, D.; Horne, W.C.; Lomri, A.; Ravesloot, J.H. Biology of the Osteoclast. Handb. Exp. Pharmacol. 1993, 107, 111-147.

88. Claes, L.; Recknagel, S.; Ignatius, A. Fracture healing under healthy and inflammatory conditions. Nat. Rev. Rheumatol. 2012, 8, 133-143. [CrossRef]

89. Einhorn, T.A.; Gerstenfeld, L.C. Fracture healing: Mechanisms and interventions. Nat. Rev. Rheumatol. 2015, 11, 45-54. [CrossRef]

90. Loi, F.; Córdova, L.A.; Pajarinen, J.; Lin, T.H.; Yao, Z.; Goodman, S.B. Inflammation, fracture and bone repair. Bone 2016, 86, 119-130. [CrossRef]

91. Do, P.A.; Lee, C.H. The Role of CDK5 in Tumours and Tumour Microenvironments. Cancers 2020, 13, 101. [CrossRef]

92. Cicenas, J.; Kalyan, K.; Sorokinas, A.; Stankunas, E.; Levy, J.; Meskinyte, I.; Stankevicius, V.; Kaupinis, A.; Valius, M. Roscovitine in cancer and other diseases. Ann. Transl. Med. 2015, 3, 135. [CrossRef]

93. Kino, T.; Ichijo, T.; Amin, N.D.; Kesavapany, S.; Wang, Y.; Kim, N.; Rao, S.; Player, A.; Zheng, Y.L.; Garabedian, M.J.; et al. Cyclindependent kinase 5 differentially regulates the transcriptional activity of the glucocorticoid receptor through phosphorylation: Clinical implications for the nervous system response to glucocorticoids and stress. Mol. Endocrinol. 2007, 21, 1552-1568. [CrossRef]

94. Pfänder, P.; Fidan, M.; Burret, U.; Lipinski, L.; Vettorazzi, S. Cdk5 Deletion Enhances the Anti-inflammatory Potential of GC-Mediated GR Activation During Inflammation. Front. Immunol. 2019, 10, 1554. [CrossRef]

95. Schmidt-Bleek, K.; Kwee, B.J.; Mooney, D.J.; Duda, G.N. Boon and Bane of Inflammation in Bone Tissue Regeneration and Its Link with Angiogenesis. Tissue Eng. Part B Rev. 2015, 21, 354-364. [CrossRef] [PubMed]

96. Liebl, J.; Zhang, S.; Moser, M.; Agalarov, Y.; Demir, C.S.; Hager, B.; Bibb, J.A.; Adams, R.H.; Kiefer, F.; Miura, N.; et al. Cdk5 controls lymphatic vessel development and function by phosphorylation of Foxc2. Nat. Commun. 2015, 6, 7274. [CrossRef] 
97. Merk, H.; Zhang, S.; Lehr, T.; Muller, C.; Ulrich, M.; Bibb, J.A.; Adams, R.H.; Bracher, F.; Zahler, S.; Vollmar, A.M.; et al. Inhibition of endothelial Cdk5 reduces tumor growth by promoting non-productive angiogenesis. Oncotarget 2016, 7, 6088-6104. [CrossRef]

98. Liebl, J.; Weitensteiner, S.B.; Vereb, G.; Takacs, L.; Furst, R.; Vollmar, A.M.; Zahler, S. Cyclin-dependent kinase 5 regulates endothelial cell migration and angiogenesis. J. Biol. Chem. 2010, 285, 35932-35943. [CrossRef]

99. Liebl, J.; Krystof, V.; Vereb, G.; Takacs, L.; Strnad, M.; Pechan, P.; Havlicek, L.; Zatloukal, M.; Furst, R.; Vollmar, A.M.; et al. Anti-angiogenic effects of purine inhibitors of cyclin dependent kinases. Angiogenesis 2011, 14, 281-291. [CrossRef]

100. Peng, Y.; Lv, S.; Li, Y.; Zhu, J.; Chen, S.; Zhen, G.; Cao, X.; Wu, S.; Crane, J.L. Glucocorticoids Disrupt Skeletal Angiogenesis Through Transrepression of NF-kB-Mediated Preosteoclast Pdgfb Transcription in Young Mice. J. Bone Miner. Res. 2020, 35, 1188-1202. [CrossRef] [PubMed]

101. Tuckermann, J.; Adams, R.H. The endothelium-bone axis in development, homeostasis and bone and joint disease. Nat. Rev. Rheumatol. 2021, 17, 608-620. [CrossRef] [PubMed] 